\title{
Western Amazonian Ticapimpla (Hymenoptera: Ichneumonidae: Pimplinae): Four New Species from Colombia, Ecuador, and Peru, with a Key to Species of the Genus
}

\author{
Edgard Palacio, ${ }^{1}$ Gavin R. Broad, ${ }^{2}$ Ilari E. Sääksjärvi, ${ }^{3}$ and Anu Veijalainen ${ }^{3}$ \\ ${ }^{1}$ Laboratorio de Artrópodos, Grupo de Biotecnología, CIF, Universidad Nacional de Colombia, Apartado Aéreo 4948, Bogotá, Colombia \\ ${ }^{2}$ Department of Entomology, The Natural History Museum, Cromwell Road, London SW7 5BD, UK \\ ${ }^{3}$ Zoological Museum, Section of Biodiversity and Environmental Sciences, Department of Biology, University of Turku, \\ 20014 Turku, Finland
}

Correspondence should be addressed to Edgard Palacio, parasitoideus@yahoo.com

Received 11 June 2010; Accepted 1 September 2010

Academic Editor: Robert Matthews

Copyright (๑) 2010 Edgard Palacio et al. This is an open access article distributed under the Creative Commons Attribution License, which permits unrestricted use, distribution, and reproduction in any medium, provided the original work is properly cited.

Ticapimpla is a small genus closely related to the New World genera Acrotaphus and Hymenoepimecis. It has been previously reported from Costa Rica and Brazil. In this paper, we describe four new species: T. amazonica from Ecuador and Peru, T. carinata from Colombia and Peru, T. matamatae from Colombia, and T. soinii from Colombia, Ecuador, and Peru. All have been collected in Western Amazonia, suggesting a South American origin for the genus. A key to the known species of the genus is provided.

\section{Introduction}

The Polysphincta group of genera (tribe Polysphinctini sensu Townes, [1]) is of great interest as the species are koinobiont ectoparasitoids developing on active spiders (see, e.g., [2, 3]). The genus Ticapimpla was described by Gauld [4] as a monotypic genus closely related to Acrotaphus Townes and Hymenoepimecis Viereck. These three genera constitute a monophyletic assemblage [5] that can be separated from the remaining neotropical genera of the Polysphincta group by the following combination of apomorphic features: (1) occipital carina strongly raised; (2) absence of occipital notch; (3) epomia completely absent; (4) epicnemial carina absent or extremely reduced. According to Gauld [4] Ticapimpla can be distinguished from Acrotaphus + Hymenoepimecis by the densely hirsute mesoscutum and the complete submetapleural carina. Another distinctive character of the genus mentioned by Gauld-the auxiliary teeth on the tarsal claws-is also present in some species of Hymenoepimecis and, according to the material examined in the present study, at least two species of Ticapimpla possess a preapical lobe instead of the auxiliary tooth. Additionally, Ticapimpla differs from Hymenoepimecis by having the pronotum simple, without a mid-dorsal, pocketlike structure.

The only described species of the genus, T. vilmae Gauld, is known from Costa Rica and Brazil $[4,6]$. In this paper, we describe four new species of Ticapimpla from Colombia, Ecuador, and Peru. We also provide images of T. vilmae for comparison. All of the new species have been collected in the Western Amazonian basin, suggesting that Ticapimpla is a taxon of South American origin. Unfortunately, nothing is known about the biology of the genus.

\section{Material and Methods}

Morphological terminology and forms of description used in the study largely follow those of Gauld [4]. The specimens are deposited in the following collections: the entomological collection of the Instituto Alexander von Humboldt, Villa de Leyva, Colombia (IAVH), Smithsonian Institution, USA (USNM), the Natural History Museum, UK (BMNH), Departamento de Entomología, Museo de Historia Natural, Universidad Nacional Mayor de San Marcos, Lima, Peru (UNSM), and The Zoological Museum, Section of 


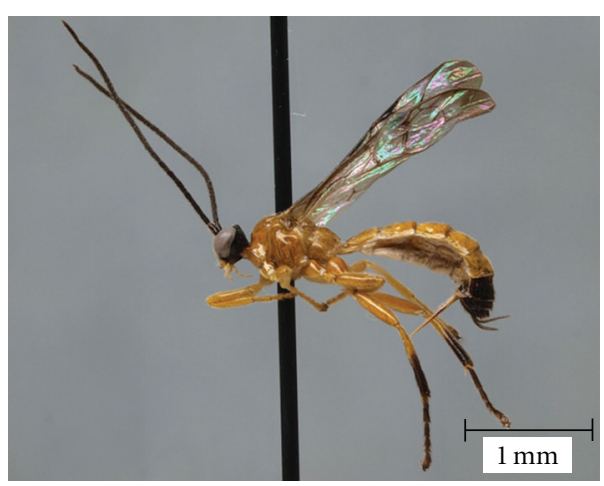

(a)

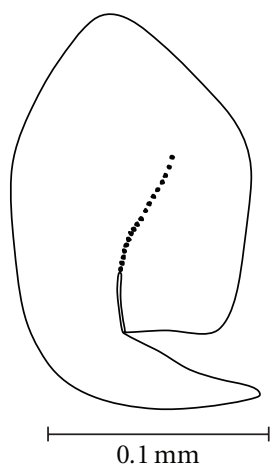

(c)

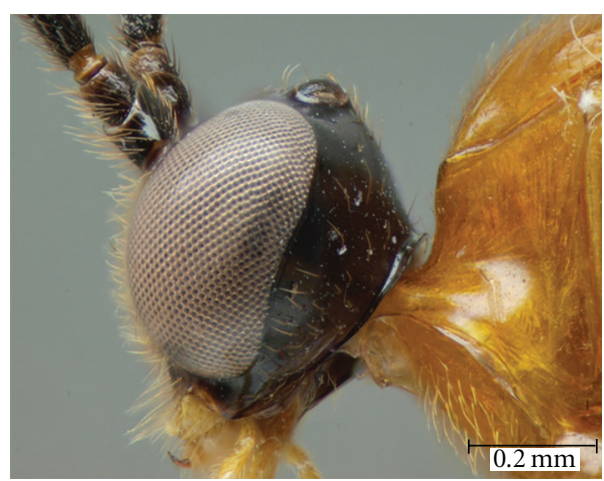

(b)

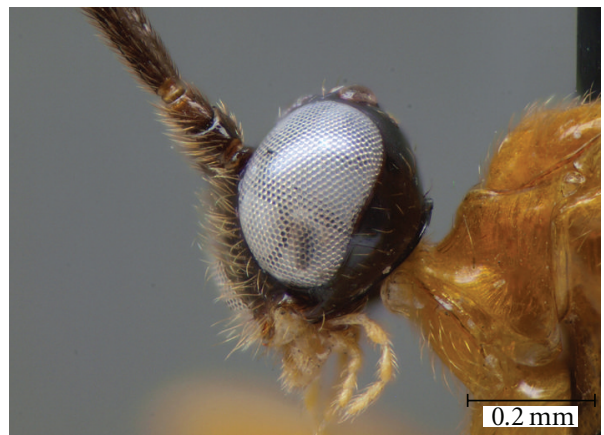

(d)

Figure 1: T. amazonica sp.n.: holotype female habitus (a), occiput detail (b), fore tarsal claw (c), and paratype male occiput detail (d).

Biodiversity and Environmental Research, Department of Biology, University of Turku, Finland (ZMUT).

The Colombian specimens examined in this study were all collected during a Malaise trap inventory carried out in Colombia between 2001 and 2003 in several natural parks of the country. This inventory is part of the Diversidad de Insectos en Áreas Protegidas Project, developed jointly by the Instituto von Humboldt (Colombia), the special administrative unit of the Colombian natural park system (UAESPNN) and the University of Kentucky, with the support of the National Science Foundation (NSF). The Ecuadorian specimens of the genus were collected by canopy fogging by Dr. Terry Erwin and his research team (USNM). Peruvian specimens were collected by Malaise trapping during a large-scale Western Amazonian ichneumonid sampling programme coordinated by the third author (e.g., [7]). All Peruvian specimens were collected in the National Reserve of Allpahuayo Mishana.

Observations were made using Leica MZ12 and Olympus SZX10 stereomicroscopes. Layer photos were taken in ZMUT using an Olympus SZX16 stereomicroscope attached to an Olympus E520 digital camera. Digital photos were combined using the Deep Focus 3.1, QuickPHOTO CAMERA 2.3, and CombineZP programmes. At BMNH, images were taken using a Zeiss Stemi SV11 stereomicroscope attached to a Canon EOS 450D digital camera and partially focused images were combined using Helicon Focus v. 4.80 software.

\section{Description of the New Species}

\subsection{Ticapimpla amazonica sp.n. (See Figures $1(a)-1(d)$ )}

Type Material. Holotype female (UNSM): Peru, Department of Loreto, Iquitos Area, Alpahuayo, Bosque Terraza. Malaise Trap H1(16). I. E. Sääksjärvi et al. leg. 7-21.XII.2000. Paratype females: 1 female (UNSM) Peru, Department of Loreto, Iquitos area, Mishana, 1-16.XII.1998, Clay, Malaise trap A1(8), I. E. Sääksjärvi et al. leg.; 1 female (ZMUT): Peru, Department of Loreto, Iquitos area, Allpahuayo, 23.I.20.II.2000, Varillal, Malaise trap G1(1), I. E. Sääksjärvi et al. leg.; 1 female (ZMUT): same locality, 24.III-16.IV.2000, Varillal, Malaise trap E3(4), I. E. Sääksjärvi et al. leg.; 1 female (BMNH): same locality, 24.I.-20.II.2000, bosque terraza, Malaise trap H1(1), I. E. Sääksjärvi et al. leg.

Paratype males: 1 male (ZMUT): Ecuador, Orellana Transect Ent. $1 \mathrm{~km} \mathrm{~S}$. Onkone Gare Camp Reserva Etnica Waorani Onkone Gare Camp 216 m, 3.X.1996, 00³9'25.7” S $076^{\circ} 27^{\prime} 10.8^{\prime \prime} \mathrm{W}, \mathrm{T}$. L. Erwin et al. leg. Fogging terra firme forest, Lot \# 1725; 1 male (USNM): same locality, 3.X.1996, $00^{\circ} 39^{\prime} 25.7^{\prime \prime} \mathrm{S} 076^{\circ} 27^{\prime} 10.8^{\prime \prime} \mathrm{W}, \mathrm{T}$. L. Erwin et al. leg., Fogging terra firme forest, Lot \# 1735. 1 male (BMNH): same locality, 2.X.1996, $00^{\circ} 39^{\prime} 25.7^{\prime \prime}$ S $076^{\circ} 27^{\prime} 10.8^{\prime \prime}$ W, T. L. Erwin et al. leg., Fogging terra firme forest, Lot \# 1708.

Female Description. Malar space at narrowest point about 0.4 times as long as basal mandibular width; lower face 
elongate, about 1.0 times as broad as high (from weak supraclypeal suture to base of antenna), rather flat, with many long, conspicuous setae; head in dorsal view with genae relatively long and narrowed behind eyes; ocelli moderately large, the lateral one separated from the eye by about 0.8 times its own diameter; occipital carina not arising from a strongly raised flange of the occiput. Pronotum relatively long, so that distance from front margin of tegula to head is about $0.6 \times$ distance from hind edge of tegula to hind margin of propodeum; mesoscutum very finely punctate; scutellum, in profile, moderately convex, posteriorly abruptly declivous; mesopleuron polished, ventrally bearing long close setae; epicnemial carina represented by a short midventral section about $1.4 \times$ the width of fore coxae. Metapleuron polished, sparsely but evenly pubescent, with setae arising from fine punctures; propodeum smooth, anteriorly and laterally with close fine setiferous punctures; propodeum, in profile, more convex than in T. carinata, anterior margin with a pair of small median tubercles; transverse groove before propodeum deep, in section U-shaped, barely interrupted laterally by raised extensions of propodeum. Tarsal claws without auxiliary tooth, instead with a preapical, flattened lobe, lobe with inner margin convex; teeth of claw simply pointed. Fore wing length $5.0-5.8 \mathrm{~mm} ; \mathrm{cu}$ - $a$ from opposite to distal of Rs\&M by about $0.2 \times$ length of $c u-a ; 2 r s-m$ about 0.2 times as long as abscisa of $M$ between $2 r s-m$ and $2 m$ $c u$; hind wing with distal abscisa of all veins more or less spectral, $c u-a$ joining subbasal cell clearly closer to $1 A$ than to $\mathrm{M}$-Cu . Metasoma moderately stout, tergite I 2.0 times as long as posteriorly broad, with lateral carina only present at extreme anterior end flanking the anterior concavity, lateral longitudinal carina present only anteriorly, reaching the spiracle; tergite II 1.1 times as long as posteriorly broad; tergite III 1.1 times as long as posteriorly broad; ovipositor $0.90-0.95$ times as long as hind tibia, lower valve proximally with a rather long, weakly convex swelling.

Head and antenna black, mouthparts and distal edge of clypeus orange. Mesosoma entirely orange. Metasoma orange, with tergites VI + and ovipositor sheath black. Anterior two pairs of legs orange; hind legs orange with distal 0.6 of tibia and entire tarsus black. Wings very faintly yellowish, the fore wing with apex and area adjacent to pterostigma very faintly infumate; pterostigma black.

Male. Similar to female but fore wing length about 3.7-4.0 $\mathrm{mm}$; tarsal claws simple, without auxiliary tooth or preapical lobe.

Variation. One of the males has the apex of the fore wings more clearly infumated than other specimens (females and males).

Diagnosis. This species can be distinguished from other species, except T. soinii sp.n., of the genus by the absence of an auxiliary tooth on female tarsal claws; instead, it has a flattened lobe resembling the common condition found in the Sericopimpla group of genera. It may be easily separated from $T$. soinii by the shape of the occiput; in T. amazonica sp.n. occipital carina does not arise from a strongly raised flange of the occiput.

Biological Notes. Nothing is known about the hosts of this species.

Etymology. The specific name refers to the distributional area of the species, the Amazonia. It also reflects the possible South American origin of the genus.

\subsection{Ticapimpla carinata sp.n. (See Figures 2(a)-2(c))}

Type Material. Holotype female (IAVH): Colombia, Department of Amazonas, PNN Amacayacu, Mocagua, $3^{\circ} 41^{\prime} \mathrm{S}$, $70^{\circ} 15^{\prime} \mathrm{W}, 150 \mathrm{~m}$ elev., D. Chota leg. Malaise trap, 26.II12.III.2001. Paratypes: 1 female (IAVH): Colombia, Department of Vaupés, R. N. Mosiro-Itajura, Caparú, $1^{\circ} 4^{\prime} \mathrm{S}$, $69^{\circ} 3^{\prime}$ W, 60 m elev., J. Pinzón leg. Malaise trap, 1-8.XII.2003; 1 female (UNSM): Peru, Department of Loreto, Iquitos area, Allpahuayo, 15.X-8.XI.2000, clay, Malaise trap J2(15), I. E. Sääksjärvi et al. leg.

Female Description. Malar space at narrowest point 0.7 times as long as basal mandibular width; lower face elongate, 1.2 times as broad as high (from supraclypeal suture to base of antenna), rather flat, with many long, conspicuous setae; head in dorsal view with genae long and narrowed behind eyes; ocelli moderately large, the lateral one separated from the eye by about 0.8 times its own diameter; occipital carina arising from a strongly raised flange of the occiput. Pronotum relatively long, so that distance from front margin of tegula to head is about $0.45-0.5 \times$ distance from hind edge of tegula to hind margin of propodeum; mesoscutum very finely punctate; scutellum, in profile, moderately convex, posteriorly abruptly declivous; mesopleuron polished, ventrally bearing long close setae; epicnemial represented by a short midventral section about $1.0 \times$ the width of fore coxae. Metapleuron polished, sparsely but evenly pubescent, with setae arising from fine punctures; propodeum smooth, anteriorly and laterally with close fine setiferous punctures, anterior margin with a pair of small median tubercles; transverse groove before propodeum deep, in section Ushaped, barely interrupted laterally by raised extensions of propodeum. Tarsal claws with a preapical auxiliary tooth; teeth of claw simply pointed. Fore wing length $6.0-6.9 \mathrm{~mm}$; $c u-a$ distal of Rs\& $r$ by about 0.1-0.2 $\times$ length of $c u-a ; 2 r s-$ $m$ about 0.2 times as long as abscisa of $M$ between $2 r s-m$ and $2 m-c u$; hind wing with distal abscisa of all veins more or less spectral, $c u-a$ joining subbasal cell distinctly closer to $1 A$ than to $\mathrm{M}-\mathrm{Cu}$. Metasoma moderately stout, tergite I 1.7 times as long as posteriorly broad, with lateral carina only present at extreme anterior end flanking the anterior concavity, lateral longitudinal carina present only anteriorly, slightly surpassing the spiracle; tergite II 1.1 times as long as posteriorly broad; tergite III 0.9 times as long as posteriorly broad; ovipositor 0.95-1.0 times as long as hind tibia, lower valve proximally with a rather long, weakly convex swelling. 


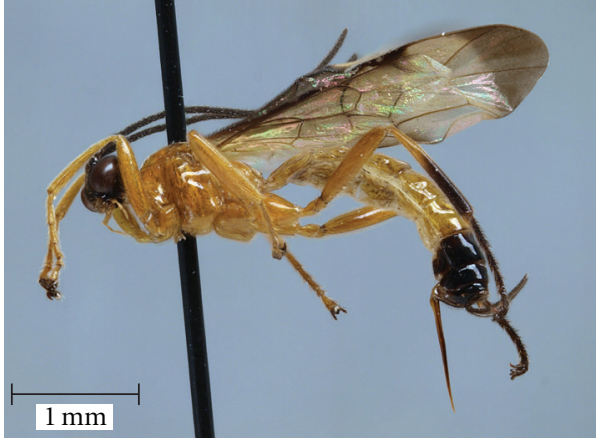

(a)

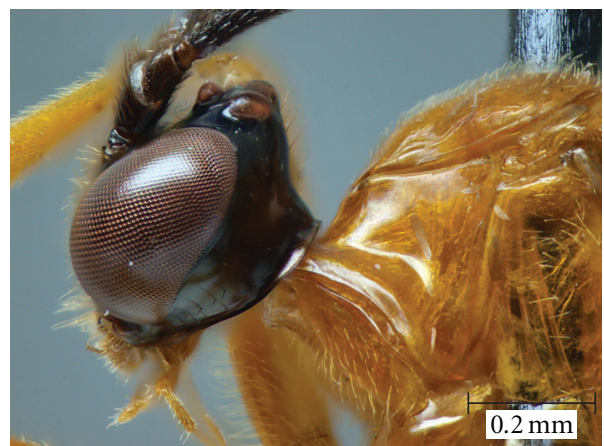

(b)

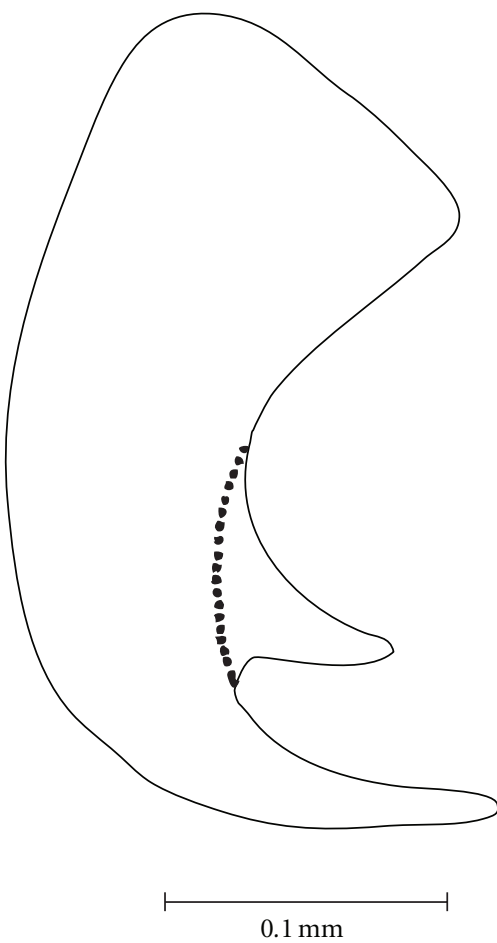

(c)

Figure 2: T. carinata sp.n.: paratype female habitus (a), occiput detail (b), and fore tarsal claw (c).

Head and antenna black, mouthparts and distal edge of clypeus orange. Mesosoma entirely orange. Metasoma orange, with tergites VI + and ovipositor sheath black. Anterior two pairs of legs orange; hind legs orange with distal 0.6 of tibia and entire tarsus black. Wings very faintly yellowish, the fore wing with apex and area adjacent to pterostigma clearly infumate; pterostigma black.

\section{Male. Unknown.}

Diagnosis. This species can be distinguished from T. vilmae Gauld and T. matamatae sp.n. by the presence of a short but discernible epicnemial carina. T. carinata sp.n. resembles $T$. amazonica sp.n. and T. soinii sp.n. in the general color pattern and by the presence of a short epicnemial carina, but has the auxiliary tooth on the female tarsal claws and a slightly slenderer metasoma. It also differs clearly from T. amazonica by the shape of the head; the occipital carina is arises from a strongly raised flange of the occiput.

Biological Notes. Nothing is known about the hosts of this species.

Etymology. The specific name refers to presence of a short ventral epicnemial carina.

\subsection{Ticapimpla matamatae sp.n. (See Figures 3(a) and 3(b))}

Type Material. Holotype female (IAVH): Colombia, Department of Amazonas, PNN Amacayacu, caño Matamata, $3^{\circ} 41^{\prime} \mathrm{S}, 70^{\circ} 15^{\prime} \mathrm{W}, 300 \mathrm{~m}$ elev., M. Kelsey leg. Malaise trap, X.1989. 


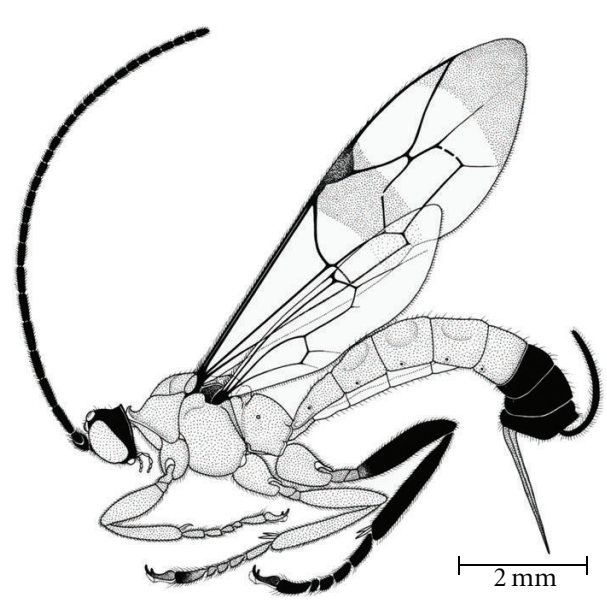

(a)

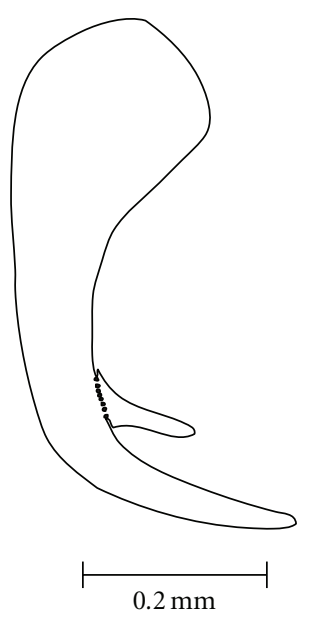

(b)

FIgURE 3: T. matamatae sp.n.: holotype female habitus (a) and fore tarsal claw (b).

Female Description. Malar space at narrowest point 0.6 times as long as basal mandibular width; lower face elongate, 0.9 times as broad as high (from supraclypeal suture to base of antenna), rather flat, laterally with scattered punctures which bear long conspicuous setae; head in dorsal view with genae long and narrowed behind eyes; ocelli moderately small, the lateral one separated from the eye by about 1.2 times its own diameter; occipital carina arising from a strongly raised flange of the occiput. Pronotum relatively long, so that distance from tegula to head is about $0.5 \times$ distance from tegula to hind margin of propodeum; mesoscutum smooth and impunctate; scutellum, in profile, moderately convex, posteriorly abruptly declivous; mesopleuron polished, ventrally bearing long close setae; epicnemial carina completely absent; metapleuron polished, sparsely but evenly pubescent, with setae arising from fine punctures; propodeum smooth, anteriorly and laterally with close fine setiferous punctures, anterior margin without median tubercles; transverse groove before propodeum deep, in section U-shaped, barely interrupted laterally by raised extensions of propodeum. Tarsal claws with a preapical auxiliary tooth; teeth of claw simply pointed. Fore wing length $9 \mathrm{~mm} ; \mathrm{cu}-a$ more or less opposite to base of Rs\&M; $2 r s-m$ about 0.2 times as long as abscisa of $M$ between $2 r s-m$ and $2 m-c u$; hind wing with distal abscisa of all veins more or less spectral, $c u-a$ joining subbasal cell clearly closer to $1 \mathrm{~A}$ than to $\mathrm{M}-\mathrm{Cu}$. Metasoma stout, tergite I 1.4 times as long as posteriorly broad, with lateral carina only present at extreme anterior end flanking the anterior concavity, lateral longitudinal carina present only anteriorly and barely reaching the spiracle; tergite II 0.8 times as long as posteriorly broad; tergite III 0.65 times as long as posteriorly broad; ovipositor 0.9 times as long as hind tibia, lower valve proximally with an inconspicuous swelling.

Head and antenna black, mouthparts orange brown. Mesosoma entirely orange. Metasoma orange, with tergites $\mathrm{VI}+$ and ovipositor sheath blackish. Anterior two pairs of legs orange; hind legs predominantly blackish, with coxa, trochanters and proximal ends of femur and tibia orange. Wings very faintly yellowish, the fore wing with apex infumate and with a weak blackish preapical band; pterostigma blackish.

Male. Unknown.

Diagnosis. This species can be distinguished from all other species of the genus by the presence of a preapical band in the anterior wings, hind femur almost entirely black, a slightly stouter metasoma, and a more inconspicuous proximal swelling on the lower ovipositor valve.

Biological Notes. Nothing is known about the hosts of this species.

Etymology. The specific name refers to the Colombian Amazonian locality surrounding "caño Matamata" where the specimen was found.

\subsection{Ticapimpla soinii sp.n. (See Figures 4(a)-4(e))}

Type Material. Holotype female (UNSM): Peru, Department of Loreto, Iquitos area, Allpahuayo, 17.XII-27.XII.2000, varillal, Malaise trap G2(18), I. E. Sääksjärvi et al. leg. Paratype females: 1 female (UNSM): Peru, Department of Loreto, Iquitos area, Allpahuayo, 24.I.-20.II.2000, bosque terraza, Malaise trap H1(1), I. E. Sääksjärvi et al. leg.; 1 female (ZMUT): same locality, 8.XI-15.XII.2000, varillal, Malaise trap E3(17), I. E. Sääksjärvi et al. leg.; 1 female (ZMUT): same locality, 8.XI-1.XII.2000, varillal, Malaise trap K2(16), I. E. Sääksjärvi et al. leg.; 1 female (BMNH): same locality, 16.VII-2.VIII.2000, bosque terraza, Malaise trap H1(10), I. E. Sääksjärvi et al. leg.; 1 female (IAVH): Colombia, Department of Putumayo, PNN La Paya, Cecilio Cocha, $0^{\circ} 7^{\prime} \mathrm{S}, 74^{\circ} 56^{\prime} \mathrm{W}, 220 \mathrm{~m}$ elev., C. Sarmiento leg. Malaise trap, 26-29.I.2002. 


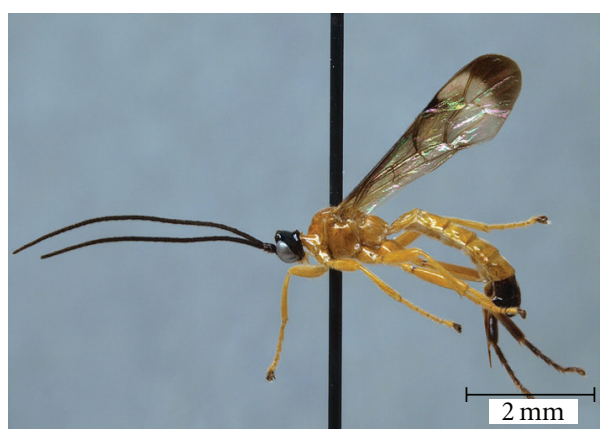

(a)

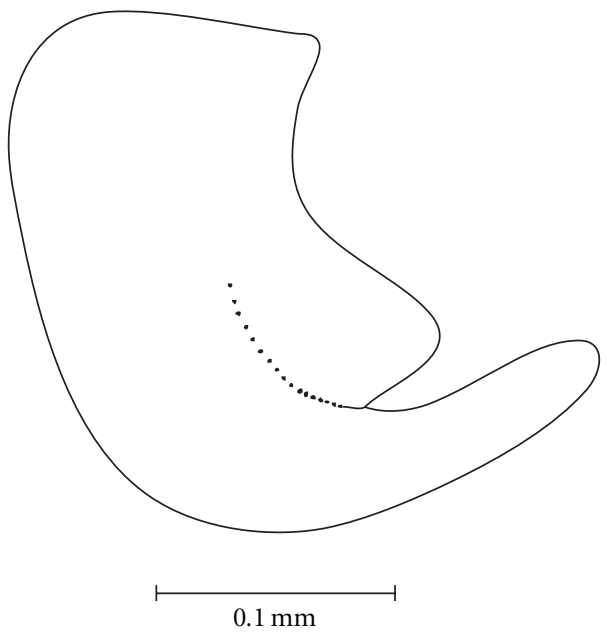

(c)

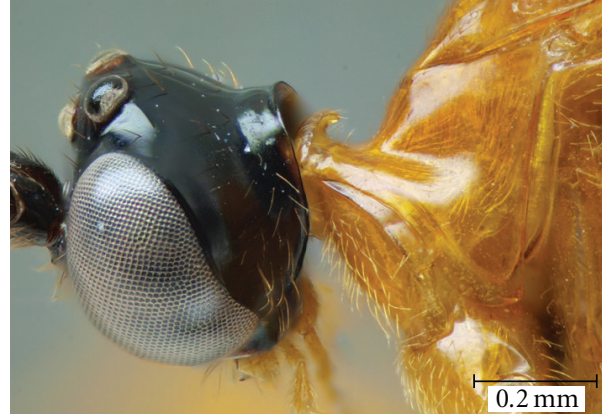

(b)

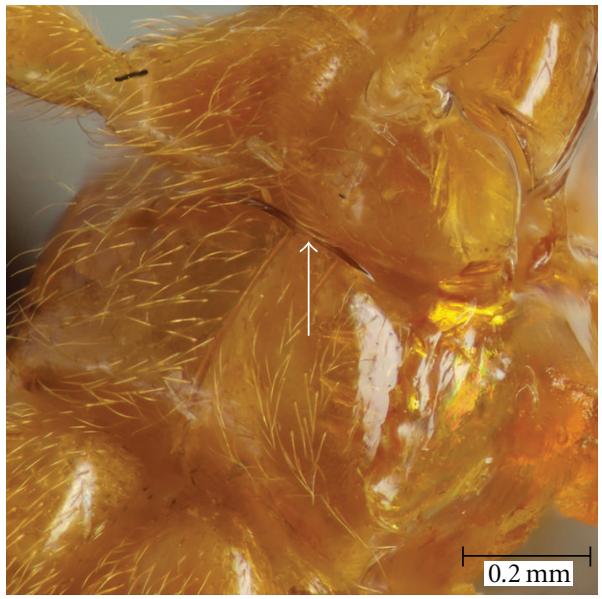

(d)

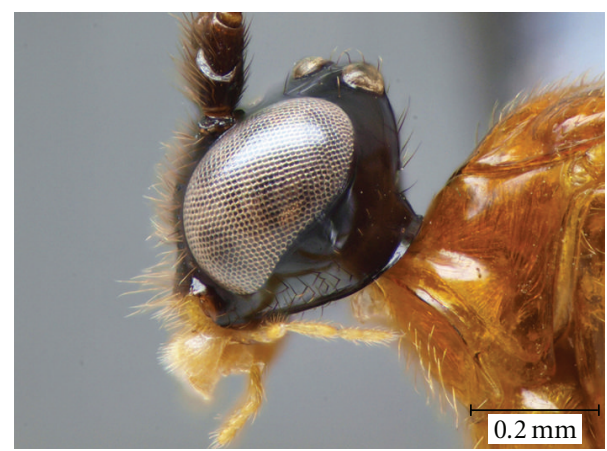

(e)

Figure 4: T. soinii sp.n.: holotype female habitus (a), occiput detail (b), fore tarsal claw (c), ventral view of epicnemium (d), and paratype male occiput detail (e).

Paratype males: 1 male (ZMUT): Ecuador, Department Orellana, Onkone Gare, $216.3 \mathrm{~m}, 00^{\circ} 39^{\prime} 25.7^{\prime \prime} \mathrm{S}$ $076^{\circ} 27^{\prime} 10.8^{\prime \prime}$ W, 22.X.2005, T. L. Erwin et al. leg., Canopy fogging, Lot \# 3062; 1 male (USNM): same locality, $216.3 \mathrm{~m}$, $00^{\circ} 39^{\prime} 25.7^{\prime \prime} \mathrm{S} 076^{\circ} 27^{\prime} 10.8^{\prime \prime}$ W, 7.X.1995, T. L. Erwin et al. leg., Canopy fogging, Lot \# 1248.

Female Description. Malar space at narrowest point about 0.4 times as long as basal mandibular width; lower face elongate, about 1.0 times as broad as high (from weak supraclypeal suture to base of antenna), rather flat, with many long, conspicuous setae; head in dorsal view with genae long and narrowed behind eyes; ocelli moderately large, the lateral one separated from the eye by about 0.8 times its own diameter; occipital carina arising from a strongly raised flange of the occiput. Pronotum relatively long, so that distance from front margin of tegula to head is about $0.6 \times$ distance from hind edge of tegula to hind margin of propodeum; mesoscutum very finely punctate; scutellum, in profile, moderately convex, posteriorly abruptly declivous; mesopleuron polished, ventrally bearing long close setae; epicnemial represented by a short midventral section about $1.0 \times$ the width of fore coxae. Metapleuron polished, sparsely but evenly pubescent, with setae arising from fine punctures; 


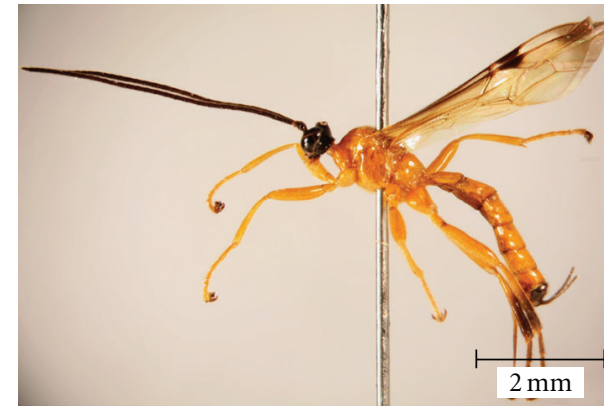

FIgURE 5: Habitus of T. vilmae, paratype female (BMNH).

propodeum smooth, anteriorly and laterally with close fine setiferous punctures; propodeum, in profile, more convex than in T. carinata, anterior margin with a pair of small median tubercles; transverse groove before propodeum deep, in section U-shaped, barely interrupted laterally by raised extensions of propodeum. Tarsal claws without auxiliary tooth, instead with a preapical, flattened lobe, lobe with inner margin clearly concave; teeth of claw broad and concave internally. Fore wing length about $5.3-6.4 \mathrm{~mm} ; c u-a$ from opposite to distal of Rse $M$ by about $0.2 \times$ length of $c u-a$; $2 r s-m$ about 0.2 times as long as abscisa of $M$ between $2 r s$ $m$ and $2 m-c u$; hind wing with distal abscisa of all veins more or less spectral, $\mathrm{Cu}-a$ joining subbasal cell clearly closer to $1 \mathrm{~A}$ than to $\mathrm{M}$-Cu. Metasoma moderately stout, tergite I 2.0 times as long as posteriorly broad, with lateral carina only present at anterior end flanking the anterior concavity and reaching about 0.3 the length of tergite I, lateral longitudinal carina present only anteriorly, reaching the spiracle; tergite II about 1.0 times as long as posteriorly broad; tergite III about 0.9 times as long as posteriorly broad; ovipositor $0.90-0.95$ times as long as hind tibia, lower valve proximally with a rather long, weakly convex swelling.

Head and antenna black, mouthparts and distal edge of clypeus orange. Mesosoma entirely orange. Metasoma orange, with tergites VI + and ovipositor sheath black. Anterior two pairs of legs orange; hind legs orange with distal 0.6 of tibia and entire tarsus black. Wings very faintly yellowish, the fore wing with apex and area adjacent to pterostigma clearly infumate; pterostigma black.

Male. Similar to female but fore wing length about $4.7 \mathrm{~mm}$; tarsal claws simple, without auxiliary tooth or preapical lobe; tergites IV and V with dark lateral markings.

Diagnosis. This species can be distinguished from other species, except $T$. amazonica sp.n., by the absence of an auxiliary tooth on female tarsal claws; instead, $T$. soinii has a flattened and internally clearly concave lobe (in T. amazonica sp.n. the lobe is internally convex). It may be easily separated from T. amazonica sp.n. by the shape of the occiput; occipital carina arises from a strongly raised flange of the occiput.

Biological Notes. Nothing is known about the hosts of this species.
Etymology. The specific name refers to Mr. Pekka Soini (1941-2004), a Finnish tropical biologist who worked for years in the National Reserve of Allpahuayo Mishana, the type locality of $T$. soinii sp.n. His scientific contributions were among the key elements in the conservation process of this megadiverse and threatened Western Amazonian rain forest.

\section{Key to the Known Species of Ticapimpla}

(1) Females-2

Males (only the males of T. amazonica and $T$. soinii are known) -6

(2) Tarsal claws with flattened, preapical lobe (Figures $1(\mathrm{c})$ and $4(\mathrm{c}))-3$

Tarsal claws with auxiliary, preapical tooth (Figures 2(c) and 3(b)) -4

(3) Occipital carina on strongly produced flange posteriorly (Figure 4(b)). Teeth of tarsal claws broad and concave internally, lobe of the claw concave (Figure $4(c))$. Fore wing with sharply defined infumate apex (Figure 4(a))—soinii sp.n.

Occipital carina on weakly produced flange posteriorly (Figure 1(b)). Teeth of tarsal claws simply pointed, not concave internally, lobe of the claw convex (Figure 1(c)). Fore wing slightly infumate apically, infumate patch not sharply defined (Figure 1(a))—amazonica sp.n.

(4) Fore wing with distinctive preapical band. Hind femur almost entirely black (Figure 3(a)). Fore wing length $>8 \mathrm{~mm}$-matamatae sp.n.

Fore wing at most with infumate area adjacent to pterostigma. Hind femur entirely orange (Figures 2(a) and 5). Fore wing length $<8 \mathrm{~mm}-5$

(5) Epicnemial carina vestigial, represented midventrally by a very short section about $0.3 \times$ the width of fore coxa. Metasoma with tergite VI orange (Figure 5) vilmae Gauld

Epicnemial carina very short but distinct, represented midventrally by a short section about $1.0 \times$ the width of fore coxa (as in Figure 4(d)). Metasoma with tergite VI black (Figure 2(a)) — carinata sp.n.

(6) Occipital carina on strongly produced flange posteriorly (Figure 4(e)). Fore wing with sharply infumate apex-soinii sp.n.

Occipital carina on weakly produced flange posteriorly (Figure 1(d)). Fore wing with slightly infumate apex—amazonica sp.n. 


\section{Discussion}

Although Pimplinae is the taxonomically best known subfamily of Ichneumonidae in the Neotropics, many species remain undescribed especially in northern South America. Moreover, it is clear that the limits of several genera are still poorly defined because the novel material found in this part of the Neotropics often represents entirely new speciesgroups or anomalous taxa that extend the morphological limits of genera. The latter is true of Ticapimpla, for which the newly described species have provided a wider concept of the genus.

Three morphological features of the genus are particularly interesting in this respect: (1) the shape of the female tarsal claws, (2) the epicnemial carina, and (3) the shape of the occiput. According to Gauld et al. [8], the preapical teeth on the female tarsal claws of pimplines represents a more derived condition than the flattened lobe. In Ticapimpla, the female tarsal claws show three different shapes: first, a short claw with a wide, flattened preapical lobe (that should be considered the plesiomorphic condition); second, a short claw with a narrower, preapical flattened lobe; finally, a large claw with a tooth-like, preapical process (the more derived condition). The absence of the epicnemial carina is generally considered a derived condition within Pimplinae and within the Polysphincta group of genera [5, 8]. The mid-ventral section of the epicnemium of Ticapimpla may have a short, but clearly distinct carina (the plesiomorphic condition), a much reduced, vestigial carina, or be simple, without any trace of carina (the more derived condition). Within the Polysphincta group of genera, the occiput is flanged in the clade Ticapimpla + (Acrotaphus + Hymenoepimecis) but simple in their closest sister group (Polysphincta) and other closely related lineages (see [5]). In Ticapimpla, the occiput varies from a weakly produced flange (possibly the plesiomorphic condition) to a very strongly produced one.

At one extreme of this range of variation is T. amazonica, possibly the less derived from within the genus, with $T$. matamatae at the other extreme-possibly the more derived one-which closely resembles some species of Acrotaphus. The only known non-Amazonian species of Ticapimpla is $T$. vilmae $[4,6]$, and it is possible that additional new species of Ticapimpla will be found in the future, further extending the limits of this genus.

\section{Acknowledgments}

The authors are indebted to Dr. Terry L. Erwin for providing them with his interesting canopy fogging samples which yielded several specimens of Ticapimpla, including the only known male specimens of the genus. The Colombian material in IAVH was collected thanks to the support of NSF grant DEB 0205982 to M. J. Sharkey and B. V. Brown. Claudia Alejandra Medina from IAVH kindly provided access to specimens under her care. The Peruvian material was collected with the help of José Alvarez, Mario Escobedo, Gerardo Lamas, Manuel Reategui, Jukka Salo, and Pekka Soini. They are grateful to the following Peruvian institutions for providing good facilities and research permits during the study: Universidad Nacional de la Amazonía Peruana, UNAP, Instituto Nacional de Recursos Naturales, INRENA, Instituto de Investigaciones de la Amazonía Peruana, IIAP and Instituto Nacional de Investigación Agraria, INIA. The Peruvian material in ZMUT was collected with the support of the Ministry of Education, Finland and the Entomological Society of Finland. Salla-Riikka Vesterlund checked the language of the discussion. The comments of Dr. Mark R. Shaw and two anonymous reviewers helped to improve the manuscript.

\section{References}

[1] H. Townes, The genera of Ichneumonidae. Part I. Ephialtinae to Agriotypinae, vol. 11 of Memoirs of the American Entomological Institute, American Entomological Institute, 1969.

[2] W. G. Eberhard, "Spider manipulation by a wasp larva," Nature, vol. 406, no. 6793, pp. 255-256, 2000.

[3] E. Nielsen, "Contributions to the life history of the pimpline spider parasites (Polysphincta, Zaglyptus, Tromatobia) (Hym. Ichneum.)," Entomologiske Meddelelser, vol. 14, pp. 137-205, 1923.

[4] I. D. Gauld, The Ichneumonidae of Costa Rica, 1, vol. 47 of Memoirs of the American Entomological Institute, American Entomological Institute, 1991.

[5] I. D. Gauld and J. Dubois, "Phylogeny of the Polysphincta group of genera (Hymenoptera: Ichneumonidae; Pimplinae): a taxonomic revision of spider ectoparasitoids," Systematic Entomology, vol. 31, no. 3, pp. 529-564, 2006.

[6] A. P. S. Loffredo and A. M. Penteado-Dias, "First record of Ticapimpla vilmae Gauld, 1991 (Hymenoptera, Ichneumonidae, Pimplinae) from Brazil," Brazilian Journal of Biology, vol. 68 , no. 4, p. 911, 2008.

[7] I. E. Sääksjärvi, S. Haataja, S. Neuvonen et al., "High local species richness of parasitic wasps (Hymenoptera: Ichneumonidae; Pimplinae and Rhyssinae) from the lowland rainforests of Peruvian Amazonia," Ecological Entomology, vol. 29, no. 6, pp. 735-743, 2004.

[8] I. D. Gauld, D. B. Wahl, and G. R. Broad, "The suprageneric groups of the Pimplinae (Hymenoptera: Ichneumonidae): a cladistic re-evaluation and evolutionary biological study," Zoological Journal of the Linnean Society, vol. 136, no. 3, pp. 421-485, 2002. 

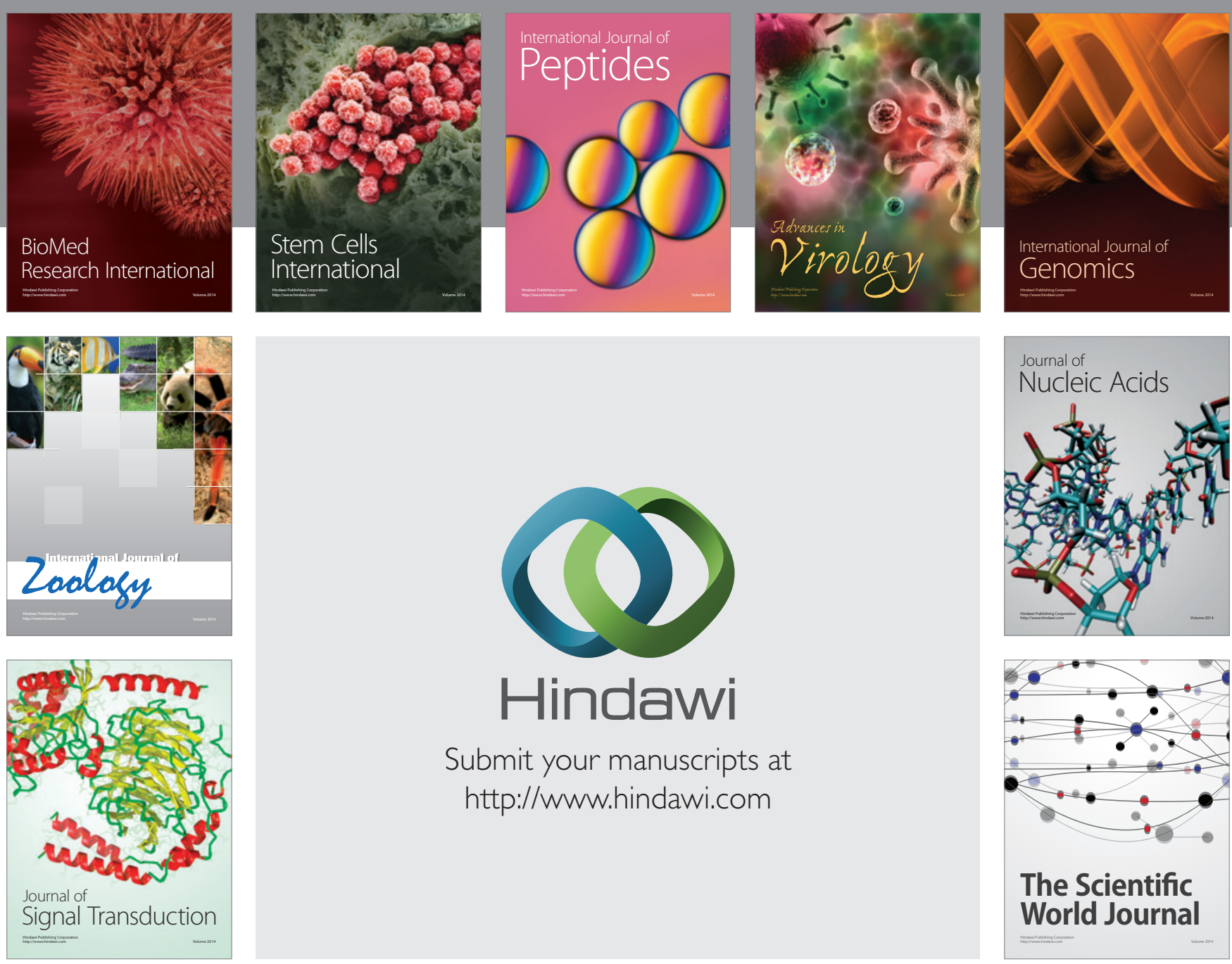

Submit your manuscripts at

http://www.hindawi.com
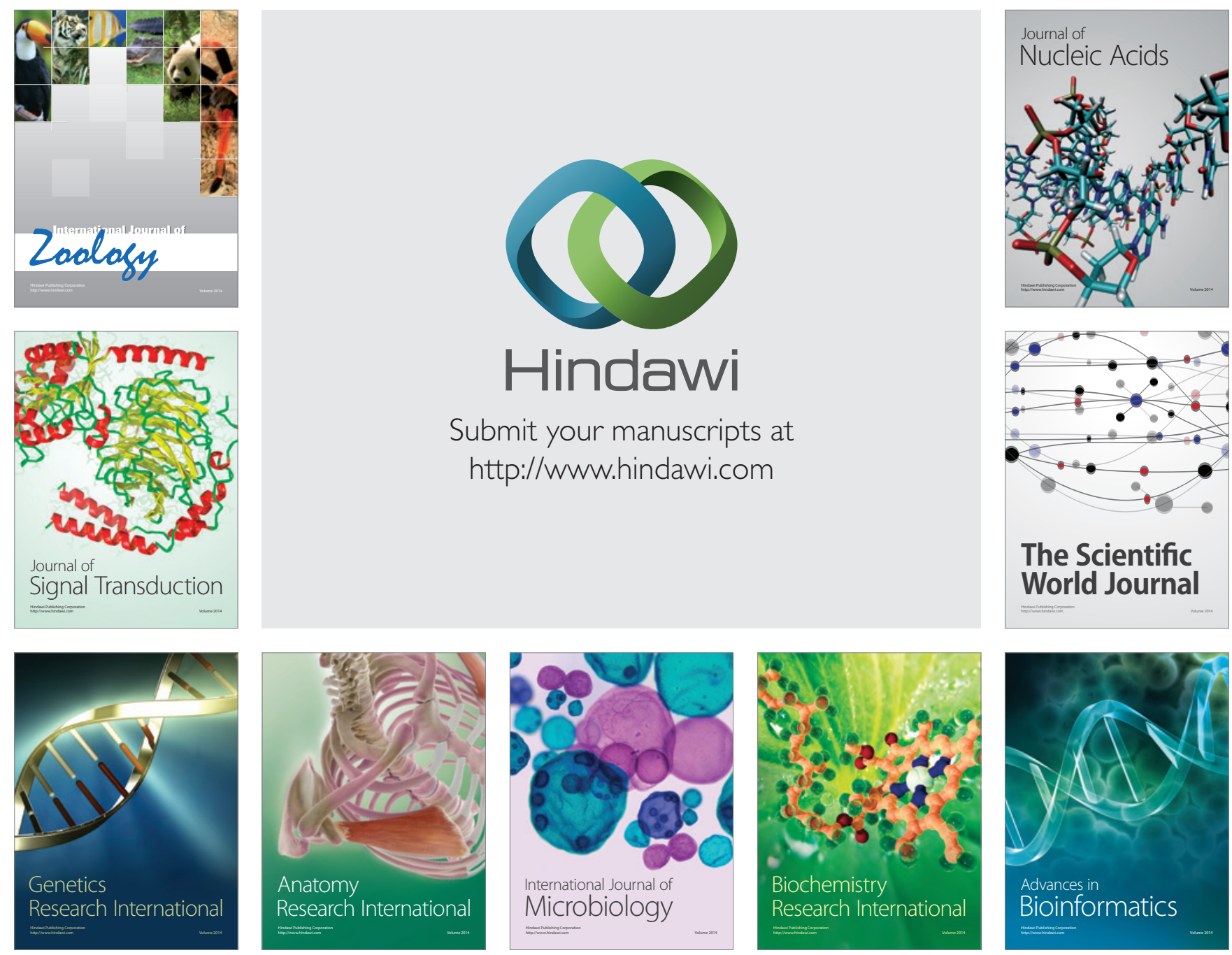

The Scientific World Journal
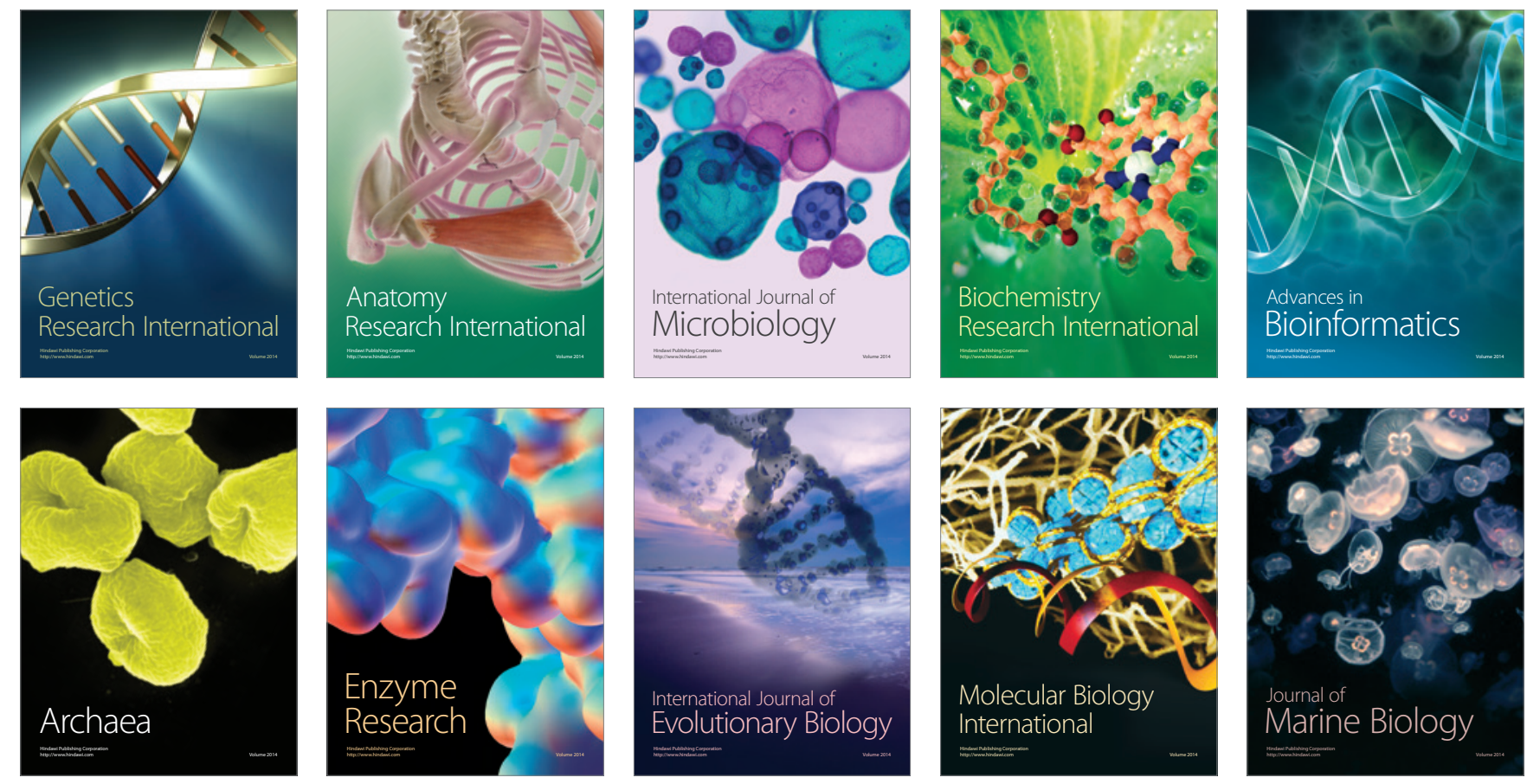